\title{
Safety of Insulin Glargine in Pregnancy
}

Sameer Ansar, Saadia Mian, Steven Roth, George Matthew Hebdon, Saleh Aldasouqi and Ved V Gossain*

Endocrinology Fellowship, College of Human Medicine, USA

\begin{abstract}
Aim: Although insulin glargine is frequently being used in pregnancy, it is not approved by the FDA as the data on its safety is limited. The aim of this study was to determine the effects of insulin glargine use in pregnancy on maternal and fetal outcomes.

Methods: From the perinatal center at Sparrow Hospital, Lansing, Michigan the charts of 92 women with diabetes (gestational diabetes, type 1 diabetes and type 2 diabetes) who were treated with insulin glargine during pregnancy were reviewed. Maternal and fetal outcomes were recorded.

Results: Eighteen women had continued pre-pregnancy insulin glargine use through pregnancy and 74 were started on insulin glargine during pregnancy. The average $\mathrm{HbA} 1 \mathrm{c}$ was $7.7 \%, 7.1 \%$ and $6.3 \%$ respectively in $1^{\text {st }}, 2^{\text {nd }}$, and $3^{\text {rd }}$ trimester. $31 \%$ of the woman had hypoglycemic episodes. No maternal deaths were reported. One pregnancy resulted in intrauterine fetal death. The rate of cesarean sections was $45 \%$ and the average age of gestation at delivery was 36 weeks. $12 \%$ of the newborns had macrosomia (defined as birth weight $>4000$ pounds), $2 \%$ had shoulder dystocia, and $7 \%$ had neonatal hypoglycemia. The data were compared to the outcome from prior studies of pregnant patients in NPH and insulin glargine.
\end{abstract}

Conclusion: We present data on maternal and perinatal outcomes with use of insulin glargine during pregnancy at our institution. Our data compares favorably with the outcome from other studies of pregnant patients using NPH insulin.

\section{Keywords: Glargine; Insulin; Macrosomia; Trimester}

\section{Introduction}

In order to improve the control of diabetes, insulin analogs with duration of action longer or shorter than traditional insulins, (regular and neutral protamine Hagedorn) have been developed and have shown to provide better glucose control and also decrease the rate of hypoglycemia in patients with diabetes [1-3]. Strict control of hyperglycemia is essential to reduce adverse maternal and fetal outcomes in pregnant woman with diabetes [4].

Insulin detemir was recently relabeled as a category "B" for the use in pregnancy on the basis of a trial involving 310 pregnant women with type 1 diabetes, with approximately half taking insulin detemir and the other half taking NPH insulin. Both groups achieved similar reductions in hemoglobin A1c. The women using insulin detemir did not experience an increased risk for fetal abnormalities [5].

Insulin glargine is being used in pregnancy "off label", it is still categorized as category " $\mathrm{C}$ ". This classification implies that: (a) either study in animals has revealed adverse effects on the fetus (teratogenic or embryocidal effects or other); (b) studies in women and animals are not available, and/or (c) there are no controlled studies in humans. Potential benefits of category $\mathrm{C}$ medications may warrant the drug's use in pregnant women despite potential downsides. The safety of insulin glargine in pregnancy is yet to be determined in large randomized trials. Unease regarding insulin glargine's use in pregnancy stems from experiments that have shown six to eight fold increased affinity for insulin growth factor (IGF)-1 receptor. This research also demonstrated increased mitogenic potency of insulin glargine compared with native insulin in human sarcoma cells [6], although it is uncertain if similar effects occur in vivo.

The aim of our study was to evaluate maternal and fetal morbidity and mortality in patients with gestational diabetes, type 1diabetes, and type 2 diabetes treated with insulin glargine during pregnancy. The study focused on episodes of fetal and maternal hypoglycemia, mode of delivery, fetal macrosomia, and shoulder dystocia.

\section{Methods}

This retrospective study included 92 women enrolled at the perinatal center at Sparrow hospital (a 733 bed hospital in Lansing, Michigan) who were treated with insulin glargine during pregnancy between 2002 and 2009. The study was approved by the institutional review board of Michigan State University.

The medical records of each woman and neonate were reviewed and data was collected for age, type of diabetes, trimester of pregnancy when insulin was started, episodes of maternal hypoglycemia, hemoglobin A1c levels achieved and units of insulin glargine used during each trimester. Maternal outcome studied included maternal deaths, episodes of preeclampsia, time and mode of delivery. Neonatal outcome included fetal death, birth weight, shoulder dystocia, hypoglycemia, and Apgar score at 1 and 5 minutes. Fetal macrosomia was defined as birth weight $>4000$ grams. Maternal and fetal hypoglycemia and preclampsia were recorded as noted in the chart.

*Corresponding author: Ved V Gossain, Program Director, Endocrinology Fellowship, College of Human Medicine, Clinical Center Building, 788 Service Road, Room B323, East Lansing, MI 48824-7016, USA, Tel: (517) 353-3730; Fax: (517) 432-1326; E-mail: Ved.Gossain@hc.msu.edu

Received November 01, 2012; Accepted December 26, 2012; Published December 29, 2012

Citation: Ansar S, Mian S, Roth S, Hebdon GM, Aldasouqi S, et al. (2013) Safety of Insulin Glargine in Pregnancy. J Diabetes Metab 4: 240. doi:10.4172/21556156.1000240

Copyright: (C) 2013 Ansar S, et al. This is an open-access article distributed under the terms of the Creative Commons Attribution License, which permits unrestricted use, distribution, and reproduction in any medium, provided the original author and source are credited. 
Citation: Ansar S, Mian S, Roth S, Hebdon GM, Aldasouqi S, et al. (2013) Safety of Insulin Glargine in Pregnancy. J Diabetes Metab 4: 240. doi:10.4172/2155-6156.1000240

Page 2 of 4

\section{Results}

From the perinatal center at Sparrow Hospital 92 women were identified taking insulin glargine during pregnancy. The data regarding the type of diabetes, trimester of pregnancy when insulin was started, average $\mathrm{HbAlc}$ achieved during the trimesters and the average glargine units during pregnancy are presented in table 1.

Twenty eight (31\%) women in our study had hypoglycemic episodes of various severities and $8 \%$ had preeclampsia. No maternal deaths were reported. One pregnancy resulted in miscarriage (at 16 weeks of gestation). The rate of caesarean section was $45 \%$ and mean gestational age was $36.2 \pm 4.38$ weeks. $12 \%$ of the neonates had macrosomia (defined as birth weight $>4000$ grams), $2 \%$ had shoulder dystocia, and 7\% had neonatal hypoglycemia. One minute Apgar score was less than 7 in $27 \%$ of patients and five minute Apgar score of less than 7 was seen in $4.7 \%$ of neonates.

The data from this study is compared to outcome from prior studies with pregnant patients on NPH insulin (Table 2) and studies with pregnant patients on insulin glargine (Table 3 ).

\section{Discussion}

Uncontrolled blood glucose in pregnancy is associated with multiple adverse maternal and fetal outcomes including congenital anomalies, macrosomia, respiratory distress, and hypoglycemia and there is clear evidence that these risks can be reduced by optimizing glucose control throughout pregnancy [4]. Therefore, it is currently recommended that women with diabetes should have their diabetes well controlled at the time of conception and throughout their pregnancy [7].

Insulin analogs with longer non-peaking profiles have been shown to decrease the rate of hypoglycemia and to provide better blood glucose control in patients with diabetes [8]. Insulin detemir was recently upgraded to a category " $\mathrm{B}$ " medication for use in pregnancy based on a prospective study [5]. Although insulin glargine is being increasingly used in pregnancy, it has not been approved by the FDA for use in pregnancy because the safety and outcomes data are limited.

Safe use of insulin glargine in pregnancy was first reported in 2002 [9] and subsequent meta-analyses have not identified any difference in maternal and fetal outcomes in patients with type1, type 2, or gestational diabetes on insulin glargine $[10,11]$. Data from our study was comparable to the data from pregnant woman on NPH obtained from prior studies (Table 2).

We show that fetal macrosomia was present in $12 \%$ newborns. In a recently published meta-analysis of 8 studies published in the Annals of Pharmacology comparing NPH and insulin glargine in pregnancy the incidence of fetal macrosomia was $16 \%$ in patients taking NPH insulin. The rate of neonatal hypoglycemia was $7 \%$ in our study compared to $19 \%$ in patients on $\mathrm{NPH}$. In particular they were no maternal

\begin{tabular}{|c|c|}
\hline Age & $30.4 \pm 5.85^{\star}$ \\
\hline Type 1 Diabetes (13) & $14 \%$ \\
\hline Type 2 Diabetes (47) & $51 \%$ \\
\hline Gestational Diabetes (32) & $35 \%$ \\
\hline $\begin{array}{l}\text { Insulin Glargine started } \\
\text { Before pregnancy } \\
\text { First trimester } \\
\text { Second trimester } \\
\text { Third trimester }\end{array}$ & $\begin{array}{l}18 \% \\
15 \% \\
39 \% \\
27 \%\end{array}$ \\
\hline $\begin{array}{l}\text { HbA1c (average) } \\
\text { First trimester } \\
\text { Seconds Trimester } \\
\text { Third trimester }\end{array}$ & $\begin{array}{l}7.73 \pm 2.37^{*} \\
7.17 \pm 1.88^{*} \\
6.36 \pm 1.38^{*}\end{array}$ \\
\hline $\begin{array}{c}\text { Insulin Glargine Units } \\
\text { First trimester } \\
\text { Second trimester } \\
\text { Third trimester }\end{array}$ & $\begin{array}{l}43 \pm 43.7^{*} \\
45 \pm 25.6^{*} \\
59 \pm 43.4^{*}\end{array}$ \\
\hline
\end{tabular}

*values shown are mean \pm SD

Table 1: Maternal Characteristics of Patients $(n=92)$.

\begin{tabular}{|c|c|c|}
\hline Maternal and fetal outcome & Our Study with patients on insulin glargine & Prior studies with patients on $\mathrm{NPH}^{*}$ \\
\hline Intrauterine deaths & $\{1 / 88\} 1.1 \%(-1.0,3.2)$ & $\{3 / 172\} 1.7 \%(-0.23,3.63) * *$ \\
\hline Preeclampsia & $\{7 / 92\} 7.6 \%(2.2,13.0)$ & $\{10 / 371\} 10.7 \%(7.36,13.8)$ \\
\hline Cesarean section & $\{40 / 88\} 45.5 \%(5.1,55.9)$ & $\{231 / 324\} 71 \%(66.0,75.9)$ \\
\hline Maternal hypoglycemia & $\{28 / 92\} 31 \%(21.6,40.4)$ & $\{20 / 205\} 9.75 \%(4.28,15.2)$ \\
\hline Mean gestational ( $\pm \mathrm{SD}$; weeks) & $36.2 \pm 4.38$ & $36.3 \pm 1.0$ \\
\hline Five minute Apgar score $<7$ & $\{3 / 64\} 4.7 \%(-0.48,9.88)$ & $\{4 / 183\} 2.1 \%(0.03,4.17)$ \\
\hline Macrosomia (>4000 grams) & $\{8 / 65\} 12.3 \%(4.4,20.2)$ & $\{26 / 166\} 15.6 \%(10.9,21.11)$ \\
\hline Shoulder Dystocia & $\{2 / 92\} 2.1 \%(-0.82,5.02)$ & $\{7 / 98\} 7.14 \%(2.09,12.19)$ \\
\hline Fetal Hypoglycemia & $\{6 / 92\} 6.5 \%(1.47,11.5)$ & $\{66 / 346\} 19 \%(14.87,23.13)$ \\
\hline
\end{tabular}

Data is presented as mean with SD or as a percentage.

In braces \{events/total number of patients studied\}

In Parenthesis (95\% confidence interval Lower and upper limit)

Data presented is unadjusted

Abbreviation: NPH: Neutral Protamine Hagedorn

${ }^{* *}$ Fetal outcome reported was perinatal mortality

${ }^{*}$ Ref: $[10,11]$

Table 2: Comparison of Maternal and fetal outcomes comparing our study with patients on insulin glargine with prior studies with patients on NPH. 


\begin{tabular}{|c|c|c|c|c|c|}
\hline Maternal and fetal outcome & $\begin{array}{l}\text { Our Study } \\
\text { Retrospective }\end{array}$ & $\begin{array}{l}\text { Di Cianni et al. } \\
\text { Retrospective [14] }\end{array}$ & $\begin{array}{l}\text { Fang et al. } \\
\text { Retrospective [15] }\end{array}$ & $\begin{array}{l}\text { Negrato } \\
\text { et al. Observational prospective [12] }\end{array}$ & $\begin{array}{l}\text { Ergman et al. } \\
\text { Retrospective [16] }\end{array}$ \\
\hline Number of patients on glargine & 92 & 43 & 52 & 55 & 65 \\
\hline Intrauterine deaths & $1.1 \%$ & 6 (abortions) & 1 (fetal death) & 0 (fetal death) & $x$ \\
\hline Preeclampsia & $7.6 \%$ & $2.3 \%$ & $1.9 \%$ & $1.8 \%$ & $25 \%$ \\
\hline Cesarean section & $45 \%$ & $79 \%$ & $53 \%$ & $x$ & $65 \%$ \\
\hline Maternal hypoglycemia & $31 \%$ & $9.3 \%$ & $1.9 \%$ & $1.8 \%$ & $x$ \\
\hline Mean gestational ( $\pm S D$; weeks) & $36.2 \pm 4.38$ & $37.2 \pm 1.5$ & $37.8 \pm 0.9$ & $37.2 \pm 1.4$ & $37.3 \pm 2.8$ \\
\hline Five minute Apgar score $<7$ & $4.7 \%$ & $X$ & $2 \%$ & 0 & $x$ \\
\hline Macrosomia (>4000 grams) & $12.3 \%$ & $21 \%$ & $x$ & $18 \%$ & $x$ \\
\hline Shoulder Dystocia & $2.1 \%$ & $x$ & $x$ & $x$ & $0 \%$ \\
\hline Fetal Hypoglycemia & $6.5 \%$ & $14.6 \%$ & $2 \%$ & $5.4 \%$ & $29 \%$ \\
\hline
\end{tabular}

$\mathrm{X}$ indicates that no data is reported in those studies

Data is presented as mean plus standard deviation.

Ref $[12,14-16]$

Table 3: Maternal and fetal outcomes in patients using insulin glargine during pregnancy.

mortality and only one fetal death (miscarriage) was observed. This compares favorably with the perinatal mortality rate of $1.7 \%$ reported in other studies on patients on NPH insulin $[10,11]$. The rate of maternal hypoglycemic episodes in our study was $31 \%$ compared to $9.8 \%$ in patients on NPH in other studies. This apparent high rate of maternal hypoglycemic episodes in our study compared to $9.8 \%$ could be explained by the fact that we included any hypoglycemic episodes whereas the studies included in the meta-analysis explicitly defined hypoglycemic episode as requiring assistance of another person [11].

The data from this study was also compared with other studies evaluating the use of insulin glargine in pregnancy (Table 3). We found 4 studies -3 retrospective and 1 observational prospective with at least 100 pregnant patients among the combined treatment groups. The outcome from those studies was compared to the outcome from our data. However, caution showed be used when making comparison between studies as the participants were not randomized, the data was from observational studies, and not all studies reported all baseline characteristics. Some of the studies, including our own were lacking in standard definitions of preeclampsia, maternal and fetal hypoglycemia and macrosomia which makes comparisons across studies difficult.

The study has certain important limitations. The rate of early pregnancy loss may be understated as this may have occurred prior to being seen at the high risk perinatal center. However it is unlikely that there may be underreporting of other fetal and maternal complications. As medical records were used as a source of data, there is the potential for missing information that may lead to bias. There was no simultaneous control group for comparison and the results were compared to other historical studies with pregnant patients on NPH. The retrospective nature and small sample size in this study may also limit clinical impact of the results.

The present study adds to the increasing number of reports indicating that use of insulin glargine in pregnancy may be associated with favorable neonatal and maternal outcomes. There has been only one observational prospective study published by Negrato et al. comparing insulin glargine with NPH insulin in 82 patients with gestational and 56 patients with pregestational diabetes [12]. The authors reported a decrease in adverse maternal and neonatal outcome with insulin glargine compared with NPH treated patients. Pantolone et al. looking at 23 reports of approx 1000 pregnancies found no consistent, adverse maternal or fetal outcome with the use of Insulin glargine [13].

\section{Conclusion}

Use of insulin glargine during pregnancy appears to be similar to other studies using NPH insulin during pregnancy. Future studies should include a prospective randomized controlled trial comparing $\mathrm{NPH}$, insulin detemir and insulin glargine to determine the benefits and adverse effects of these insulin's and to ensure the validity and applicability of the results obtained by us and others.

\section{References}

1. Ratner RE, Hirsch IB, Neifing JL, Garg SK, Mecca TE, et al. (2000) Less hypoglycemia with insulin glargine in intensive insulin therapy for type 1 diabetes. U.S. Study Group of Insulin Glargine in Type 1 Diabetes. Diabetes Care 23: 639-643.

2. Bolli GB, Di Marchi RD, Park GD, Pramming S, Koivisto VA (1999) Insulin analogues and their potential in the management of diabetes mellitus. Diabetologia 42: 1151-1167.

3. Brunelle BL, Llewelyn J, Anderson JH Jr, Gale EA, Koivisto VA (1998) Metaanalysis of the effect of insulin lispro on severe hypoglycemia in patients with type 1 diabetes. Diabetes Care 21: 1726-1731.

4. Drexel H, Bichler A, Sailer S, Breier C, Lisch HJ, et al. (1988) Prevention of perinatal morbidity by tight metabolic control in gestational diabetes mellitus. Diabetes Care 11: 761-768.

5. Mathiesen ER, Hod M, Ivanisevic M, Duran Garcia S, Brøndsted L, et al. (2012) Maternal efficacy and safety outcomes in randomized controlled trial comparing insulin detemir with NPH insulin in 310 pregnant women with type 1 diabetes. Diabetes Care 35: 2012-2017.

6. Kurtzhals P, Schäffer L, Sørensen A, Kristensen C, Jonassen I, et al. (2000) Correlations of receptor binding and metabolic and mitogenic potencies of insulin analogs designed for clinical use. Diabetes 49: 999-1005.

7. (2012) Standards of medical care in Diaetes-2012. Diabetes Care 35: S11-S63.

8. Hirsch IB (2005) Insulin analogues. N Eng J Med 352:174-183.

9. Devlin JT, Hothersall L, Wilkis JL (2002) Use of insulin glargine during pregnancy in a type 1 diabetic woman. Diabetes Care 25: 1095-1096.

10. Pollex E, Moretti M, Koren G, Feig DS (2011) Safety of Insulin Glargine Use in Pregnancy: A Systematic Review and Meta-Analysis. The annals of Pharmacotherapy 45: 9-16.

11. Lepercq J, Lin J, Hall GC, Wang E, Dain MP et al. (2012) Meta-Analysis of Maternal and Neonatal Outcomes Associated with the Use of Insulin Glargine versus NPH Insulin during Pregnancy. Obstet Gynecol Int 2012: 649070.

12. Negrato CA, Rafacho A, Negrato G, Teixeira MF, Araújo CA, et al. (2010) Glargine vs. NPH insulin therapy in pregnancies complicated by diabetes: an observational cohort study. Diabetes Res Clin Pract 89: 46-51.

13. Pantalone KM, Faiman C, Olansky L (2011) Insulin glargine use during pregnancy. Endocr Pract 17: 448-455. 
Citation: Ansar S, Mian S, Roth S, Hebdon GM, Aldasouqi S, et al. (2013) Safety of Insulin Glargine in Pregnancy. J Diabetes Metab 4: 240. doi:10.4172/2155-6156.1000240

Page 4 of 4

14. Di Cianni G, Torlone E, Lencioni C, Bonomo M, Di Benedetto A, et al. (2008) Perinatal outcomes associated with the use of glargine during pregnancy. Diabet Med 25: 993-996.

15. Fang YM, MacKeen D, Egan JF, Zelop CM (2009) Insulin glargine compared with Neutral Protamine Hagedorn insulin in the treatment of pregnant diabetics. J Matern Fetal Neonatal Med 22: 249-253.

16. Egerman RS, Ramsey RD, Kao LW, Bringman JJ, Haerian H, et al. (2009) Perinatal outcomes in pregnancies managed with antenatal insulin glargine. Am J Perinatol 26: 591-595. 